\title{
What is new for 2020
}

Another year is beginning and here we are again welcoming all the people involved with the activities of the Journal of the Brazilian Chemical Society. Before I announce what is coming for 2020, I should mention that the last year was quite special for our journal. In 2019, we celebrated our $30^{\text {th }}$ Anniversary, and to comemorate that moment, we had two main activities: first the Workshop during the $42^{\text {nd }}$ Annual Meeting of the Brazilian Chemical Society, and second the special number of our journal dedicated to the Brazilian women who have contributed with science in Brazil, particularly those involved with chemistry. To our grateful surprise, a great number of Brazilian women submitted their paper to this special number and, in the end, instead of a single number dedicated to them, we published three issues (30-10, 30-11 and 30-12), a wonderful reward for the journal and for all people with some involvement with JBCS. ${ }^{1}$

As it happens every year, for 2020, I would like to announce some of the changes we had in the JBCS. The first is regarding the change of editor for environmental chemistry, our collaborator Prof Dr Vanessa Hatje from the Federal University of Bahia being replaced by Prof Dr Maria Cristina Canela from the Norte Fluminense State University. Last year, we also introduced some modifications on the manuscript submission process, one of them is that authors have to use their ORCID as piece of identification for the submission of their manuscript. Another is that authors have now the option to choose which editor they want to take care of their manuscript. If possible, they will have their wish attended. We also have news for the reviewers who will have the recognition of their work for the journal if they desire, in an initiative involving Publons. The JBCS also decided to publish reviewers' names in the last issue of the year (12), already made in the issue 30-12. The last information was the launching of two more Virtual Thematic Collections referring to Renewable Energy and Chemometrics.

These changes will have no effect if we do not count on the collaboration of authors and reviewers'. We need their support to keep the high standards of the journal. We are very thankful to their work as we are thankful to the editors and advisory board who have devoted part or their time to JBCS.

We cannot forget that since the beginning of last year we have been living under a new government who has done some financial changes that has affected negatively science and technology in the country. We hope to overcome this difficult time, and that, in the near future, we will recover our capacity of investment in education, science and technology. For that, it is important that all of us stay mobilized and alert to push the decision makers in their activities.

Enjoy reading our journal and let's work for a wonderful 2020 .

Paulo Cezar Vieira Editor-in-chief of the Journal of the Brazilian Chemical Society Universidade de São Paulo (USP), Ribeirão Preto-SP, Brazil

\section{Reference}

1. Vargas, M. D.; Soares, J. F.; J. Braz. Chem. Soc. 2019, 30, 1999. 